\title{
Bioavailability of a Capsaicin Lipid Multi-particulate Formulation in Rats
}

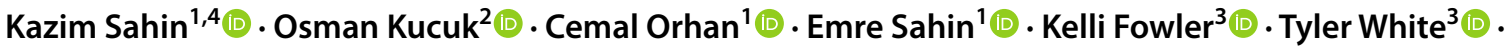 \\ Shane Durkee ${ }^{3}$. $\cdot$ Aouatef Bellamine ${ }^{3}(\mathbb{D}$
}

Accepted: 14 June 2021 / Published online: 21 July 2021

(C) The Author(s) 2021, corrected publication 2021

\begin{abstract}
Background and Objective Because of the stomach-burning sensation it induces, capsaicin has been used at relatively low doses as a nutritional supplement, which has limited its bioavailability. The objective of this study was to investigate the serum bioavailability of capsaicin supplementation with or without a lipid multi-particulate (LMP) formulation.

Methods Thirty-five rats were divided into five groups and administered capsaicin at either $0.2 \mathrm{or} 1 \mathrm{mg} / \mathrm{kg}$ with or without the LMP formulation. Capsaicin bioavailability was assessed based on the area under the concentation-time curve (AUC), the time to peak concentration $\left(T_{\max }\right)$, and the peak serum concentration $\left(C_{\max }\right)$.

Results For each formulation, the capsaicin $C_{\max }$ was reached at $90 \mathrm{~min}$ and decreased thereafter. Serum capsaicin concentrations were greater in rats administered the higher dose of capsaicin $(1 \mathrm{mg} / \mathrm{kg})$ in the LMP formulation at all measurement times $(P \leq 0.05)$. The AUC showed a significant increase, about $20 \%$, when capsaicin was administered in the LMP formulation at the high dose $(P=0.002)$. The $T_{\max }$ for oral capsaicin was similar whether or not administration was via the LMP formulation $(P=0.163)$. However, the $C_{\max }$ of capsaicin increased in a dose-dependent manner $(P<0.05)$. Although the LMP formulation of the high dose of capsaicin resulted in a numerically higher $C_{\max }$, it was not statistically significantly higher $(P=0.068)$.

Conclusions The present work demonstrated that administration of capsaicin via the LMP formulation significantly impacted the pharmacokinetic parameters and the serum bioavailability of orally administered $1 \mathrm{mg} / \mathrm{kg}$ capsaicin in rats. The bioavailability of capsaicin in humans may also be increased by using the LMP formulation.
\end{abstract}

\author{
Kazim Sahin \\ nsahinkm@yahoo.com \\ Osman Kucuk \\ okucuk@erciyes.edu.tr \\ Cemal Orhan \\ corhan@firat.edu.tr \\ Emre Sahin \\ esahin@bingol.edu.tr \\ Kelli Fowler \\ kelli.fowler@lonza.com \\ Tyler White \\ tyler.white@lonza.com
}

Shane Durkee

shane.durkee@lonza.com

Aouatef Bellamine

aouatef.bellamine@lonza.com

1 Department of Animal Nutrition, Faculty of Veterinary Medicine, Firat University, Elazig, Turkey

2 Department of Animal Nutrition, Faculty of Veterinary Medicine, Erciyes University, Kayseri, Turkey

3 Lonza Consumer Health Inc., Morristown, NJ, USA

4 Veterinary Faculty, Firat University, 23119 Elazig, Turkey 


\section{Key Points}

Lipid multi-particulates (LMPs) are an innovation aimed at improving the performance of pharmaceutical products, and have been used in consumer health and nutrition applications.

The present work showed that the bioavailability of orally supplemented capsaicin was significantly increased (by 20\%) when it was administered in an LMP formulation at a dose of $1 \mathrm{mg} / \mathrm{kg}$. LMP administration was found to improve the bioavailability of capsaicin.

\section{Introduction}

Capsaicin is an active ingredient present in fruits of various pepper variants (genus Capsicum). Capsaicin supplementation has been shown to have multiple biological benefits in animals and humans. These benefits include pain and inflammation relief, thermoregulation, inhibition of adipogenesis and fat accumulation, and the prevention of cancer, cardiovascular problems, and Alzheimer's disease [1-6].

As it is a hydrophobic molecule, capsaicin has a long hydrophobic tail by which it diffuses through cellular membranes. However, it is believed that this hydrophobic characteristic of capsaicin lowers its affinity for its transport system and is responsible for its relatively short half-life and limited bioavailability [7, 8]. While almost insoluble in water, capsaicin is readily soluble in ethanol, methanol, acetone, chloroform, and alkaline aqueous solutions [9]. As reported in previous studies [10], its low water solubility combined with its significant first-pass metabolism, resulting in a short half-life via intravenous administration, leads to low serum bioavailability of capsaicin. This has prevented thorough investigation of capsaicin and has limited its clinical applications. Capsaicin is known for the burning sensation it induces once it reaches the stomach [11]. However, when fat-soluble capsaicin extracts were included in lipid formulations, a delay in the capsaicin-related burning sensation was noticed; this delay was most likely due to the delayed release of capsaicin beyond the stomach [12]. For this reason, researchers have used different techniques such as encapsulation [13], micelles [14], microemulsion [15], and nanoparticles [16] to increase the solubility and bioavailability of capsaicin while delaying its release. Meanwhile, lipid multi-particulates (LMPs) have received considerable attention recently due to their various potential applications and advantages; for instance, they allow the controlled release of small molecules [17] and enhance the bioavailability of drugs [18]. An LMP is a fat-based matrix multiparticulate comprising spherical particulates with a typical diameter of between 50 and 300 microns that incorporate the drug or the ingredient of interest and are produced by a melt-congealing process [19]. LMP technology is believed to be a promising method of enhancing the bioavailability of drugs [18]. Because of the hydrophobic characteristics of capsaicin, an LMP formulation of capsaicin might increase its delivery into the circulation, resulting in higher bioavailability and potentially better efficacy. Absorption is of particular interest, as numerous studies have reported that non-LMP capsaicin shows a wide range of biological activity, despite the limitation that only small doses can be administered in order to avoid the reported stomach-burning sensation [11]. However, the serum bioavailability of capsaicin with an LMP formulation has not yet been fully investigated. Therefore, the objective of the present work was to compare the oral bioavailability (by assessing the area under the concentation-time curve) of capsaicin with or without an LMP formulation. The time to peak concentration $\left(T_{\max }\right)$ and the peak serum concentration $\left(C_{\max }\right)$ were also measured.

\section{Materials and Methods}

\subsection{Chemicals and Reagents}

Capsaicin (capsaicinoids 40\%, capsaicin $23.36 \%$ w/w; batch no. C180528) from Capsicum annuum fruit extract was supplied by Sabinsa Corporation (NJ, USA). The capsaicin lipid multi-particulate formulation used in this work consisted of active components (capsaicin $\mathrm{CO}_{2}$ extract $5 \%$, capsaicin extract $26.25 \%$ ) and excipients (candelilla wax $38.35 \%$, croscarmellose sodium $30.4 \%$ ). This lipid multi-particulate solution (from Lonza Health Consumer Inc., NJ, USA) was prepared as follows: the candelilla wax and capsaicin extract were combined and heated at $85{ }^{\circ} \mathrm{C}$, stirring with a center-mount mixer at $3000 \times g$ for $1 \mathrm{~h}$ or until the solution was homogeneous. The capsaicin $\mathrm{CO}_{2}$ extract and croscarmellose sodium were then added at $70{ }^{\circ} \mathrm{C}$. The internal standard (IS), capsaicin (CAS: 404-86-4, purity 98.5\%, HPLC), was supplied by Merck (Supelco, Darmstadt, Germany). All other chemicals were purchased from Sigma-Aldrich (Darmstadt, Germany). Purified water from an ultrapure system (Human Power I, Seoul, Korea) was used throughout the experiment.

\subsection{Animals and Experimental Design}

Thirty-five male Wistar rats ( 8 weeks old; mean weight of $180 \pm 20 \mathrm{~g}$ ) were purchased from Firat University Experimental Research Centre. Animals were kept in a room maintained at a specific temperature $\left(23 \pm 2{ }^{\circ} \mathrm{C}\right)$ and humidity $(55 \pm 10 \%)$ and under a $12 / 12 \mathrm{~h}$ light/dark cycle throughout the experiment. 
The study was approved by the Animal Ethics Committee of Firat University (27/05/2020-393056) and conducted in accordance with the standard ethical guidelines for laboratory animal use and care. Rats were randomly allocated to five groups ( $n=7$ each) that received the following treatments: no treatment (control group), $0.2 \mathrm{mg} / \mathrm{kg}$ bw of capsaicin (CAPS 1 group), $1 \mathrm{mg} / \mathrm{kg}$ bw of capsaicin (CAPS 2 group), $2 \mathrm{mg} / \mathrm{kg}$ bw of capsaicin in the LMP formulation (assuming 10\% incorporation) (LMP CAPS 1 group), and $10 \mathrm{mg} / \mathrm{kg}$ bw of capsaicin in the LMP formulation (assuming 10\% incorporation) (LMP CAPS 2 group). Thus, capsaicin was administered at a dose of either 0.2 or $1 \mathrm{mg} / \mathrm{kg}$, regardless of the formulation considered. The same volume $(5 \mathrm{~mL} / \mathrm{kg}$ bw) was administered in all cases. Water and a regular chow diet were offered ad libitum.

Capsaicin is taken as a supplement at $2 \mathrm{mg} /$ day on average in humans [20], which translates to a dose of $0.2 \mathrm{mg} / \mathrm{kg}$ in rats. Therefore, the doses of 0.2 and $1 \mathrm{mg} / \mathrm{kg}$ used in this study correspond to human-equivalent doses of $0.033 \mathrm{mg} /$ $\mathrm{kg}$ or $2 \mathrm{mg} /$ day and $0.16 \mathrm{mg} / \mathrm{kg}$ or $10 \mathrm{mg} /$ day, respectively.

\subsection{Chromatographic Conditions}

Serum capsaicin concentrations from the oral administration of capsaicin alone or formulated in the LMP were quantified by HPLC (Shimadzu Co. Ltd., Kyoto, Japan). Chromatographic separation was achieved using a pump (LC-20AD), an ultraviolet-visible detector (SPD-20A), an Inertsil ODS-3 C18 column $(250 \times 4.6 \mathrm{~mm}, 5 \mu \mathrm{m})$, a column oven (CTO10ASVP), an autosampler (SIL-20A), and a degasser. The capsaicin in the samples was separated by isocratic elution using a mobile phase consisting of a mixture of methanol and water $(60: 40 \mathrm{v} / \mathrm{v})$ in the $\mathrm{C} 18$ column, and was then detected at $280 \mathrm{~nm}$ [21]. This method was validated for system suitability, selectivity, calibration range, accuracy, repeatability, and intermediate precision of the peak area measurement in accordance with the current ICH guidelines [22]. Accuracies were found to be 96.5 and $99.7 \%$ for capsaicin and dihydrocapsaicin, respectively. The limits of detection were 3.2 and $5.1 \mathrm{ng} / \mathrm{mL}$ for capsaicin and dihydrocapsaicin. Retention times were $6.05 \mathrm{~min}$ for capsaicin (CV\% $=2.8 \%)$ and $7.44 \mathrm{~min}$ for dihydrocapsaicin $(\mathrm{CV} \%=3.1 \%)$.

\subsection{HPLC Method Validation}

A standard stock solution of capsaicin $(100 \mu \mathrm{g} / \mathrm{mL})$ was prepared by dissolving the chemical in methanol. Serial dilutions in methanol were prepared in order to make working standard solutions in the concentration range $0.5-100 \mu \mathrm{g} / \mathrm{mL}$. The internal standard (IS) stock solution $(1 \mathrm{mg} / \mathrm{mL})$ was dissolved in methanol. All solutions were stored at $4{ }^{\circ} \mathrm{C}$ and brought to room temperature before use. For the preparation of serum calibration curves, $10 \mu \mathrm{L}$ of each standard working solution (concentration range: $0.5-100 \mu \mathrm{g} / \mathrm{mL}$ ) were evaporated in tubes under a gentle stream of nitrogen at $50{ }^{\circ} \mathrm{C}$. After the addition of $0.1 \mathrm{~mL}$ blank serum and mixing for $10 \mathrm{~s}$ on a vortex mixer, the samples were subjected to extraction and analysis. SI concentrations in serum were $0.05,0.1,0.25,0.5$, $1,2.5,5$, and $10 \mu \mathrm{g} / \mathrm{mL}$. Samples were quantified using the ratio of the peak area of capsaicin to that of the IS. Peak area ratios were plotted against standard capsaicin concentrations, and the equation of the least-squares regression line was used to determine serum capsaicin concentrations. All the quality control samples (QCs) used in the validation and during the pharmacokinetic study were prepared in the same way, making use of the calibration standard curve, before analysis.

\subsection{Sample Preparation}

The samples were prepared using a previously reported procedure [21]. Each serum sample was thawed in a water bath at $37^{\circ} \mathrm{C}$, and $200 \mu \mathrm{L}$ of the serum sample were transferred to a $5 \mathrm{~mL}$ plastic test tube. After the addition of $20 \mu \mathrm{L}$ of IS (50 $\mu \mathrm{g} / \mathrm{mL}$ ), the sample was homogenized in ice-cold acetone and centrifuged at $3000 \times g$ for $10 \mathrm{~min}$. The supernatant fluid was evaporated, and the residue was dissolved in $2.0 \mathrm{~mL}$ of methanol. Additional protein precipitation was achieved by the addition of $1.0 \mathrm{~mL}$ of $70 \%$ perchloric acid. Samples were centrifuged again at $20,000 \times g$ for $5 \mathrm{~min}$. The upper organic layer was evaporated to dryness using an evaporator at $40{ }^{\circ} \mathrm{C}$. The residue was dissolved in $100 \mu \mathrm{L}$ of the mobile phase, vortex mixed, and then a $50 \mu \mathrm{L}$ aliquot of the solution was injected three times into the HPLC system for analysis.

\subsection{Pharmacokinetic Parameters}

On the testing day, $0.4 \mathrm{~mL}$ blood samples were collected immediately before and 30,60, 90, 120, and 180 min after the oral administration of capsaicin with or without the LMP under anesthesia (intramuscular injection of $6 \mathrm{mg} / \mathrm{kg}$ xylazine hydrochloride and $85 \mathrm{mg} / \mathrm{kg}$ ketamine hydrochloride). The blood samples were collected in Eppendorf tubes and centrifuged at $13,680 \times \mathrm{g}$ for $10 \mathrm{~min}$. A $0.2 \mathrm{~mL}$ volume of serum was obtained and stored at $-20^{\circ} \mathrm{C}$ until analysis. The AUC was estimated for capsaicin alone and for capsaicin formulated in the LMP. Pharmacokinetic analysis was conducted using the actual collection times of the post-dose samples. Pharmacokinetic data were calculated by the noncompartmental method. $T_{\max }$ and $C_{\max }$ were determined from the individual serum concentration-time profiles. The AUC of the serum concentration-time profile from 0 to $180 \mathrm{~min}$ was calculated using the linear up-log down trapezoidal method.

\subsection{Statistical Analyses}

Data are expressed as the mean \pm standard deviation (SD). All statistical calculations were performed using the SPSS 
Statistics 21.0 software (IBM SPSS Inc., Chicago, IL, USA). Differences between groups were evaluated for statistical significance using the one-way ANOVA test followed by Tukey's post-hoc test. $P<0.05$ was considered statistically significant.

\section{Results}

The analytical peaks of capsaicin with or without the LMP formulation and the internal standard were resolved with good symmetry in blank serum (Fig. 1). The retention time of capsaicin, $6.05 \mathrm{~min}$, did not change when the LMP formulation was used. The dihydrocapsaicin used as an internal standard had a retention time of $7.44 \mathrm{~min}$. No endogenous sources of interference were observed at the retention times of the analytes.

Capsaicin administered alone or in the LMP formulation was detected in all serum samples. The mean serum concentration-time profiles of capsaicin with and without the LMP formulation are shown in Fig. 2. Serum capsaicin concentrations were greatest in rats that were orally administered the higher dose of capsaicin $(1 \mathrm{mg} / \mathrm{kg})$, CAPS 2 in the LMP formulation at all measurement times $(P \leq 0.05)$. The CAPS 2 group had significantly higher serum capsaicin concentrations than the lower does, CAPS 1 group at $90 \mathrm{~min}$ $(P<0.0001)$. Also, the serum capsaicin concentrations were statistically significantly higher in the LMP CAPS 2 group than in the LMP CAPS 1 group $(P<0.0001)$. The high capsaicin dose $(1 \mathrm{mg} / \mathrm{kg})$ formulated in the LMP yielded the highest serum capsaicin concentrations at all measurement times $(P<0.0001$ in comparisons with the CAPS 1, CAPS 2 and LMP CAPS 1 groups), with the highest concentrations achieved at $90 \mathrm{~min}$ and a gradual decrease in concentration occurring thereafter. As expected, the high capsaicin dose (1 $\mathrm{mg} / \mathrm{kg}$ ) with or without the LMP led to higher serum capsaicin concentrations than the low capsaicin dose.

Similar results were observed in the current study with the AUC data (Table 1), where the highest bioavailability

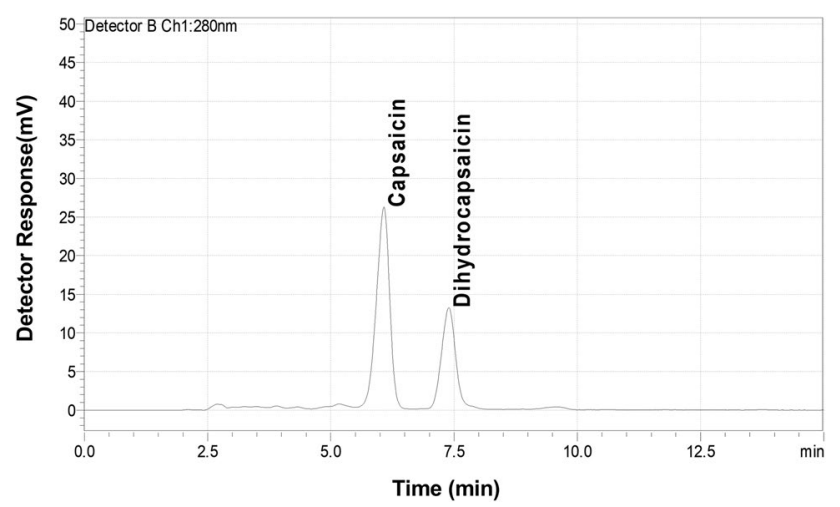

Fig. 1 The retention times of capsaicin and dihydrocapsaicin (6.05 and $7.44 \mathrm{~min}$, respectively) in a standard solution was obtained with the high capsaicin dose in the LMP formulation. Capsaicin at $1 \mathrm{mg} / \mathrm{kg}$ in the LMP formulation was significantly more bioavailable than the same dose without the LMP formulation. At the high dose, capsaicin formulated in the LMP had 20\% higher bioavailability than the same dose without the LMP formulation $(P=0.002)$. For the lower dose of capsaicin $(0.2 \mathrm{mg} / \mathrm{kg})$, using the LMP formulation did not significantly enhance the bioavailability of capsaicin $(P=0.863)$. These data indicate that the LMP formulation increases the bioavailability of capsaicin when given at $1 \mathrm{mg} / \mathrm{kg}$.

At both doses, the time to peak serum concentration $\left(T_{\max }\right)$ for oral capsaicin did not depend on whether the LMP formulation was used (Table 1; $P=0.163$ ). The peak serum concentration $\left(C_{\max }\right)$ of capsaicin increased with increasing the dose (Table $1 ; P<0.0001$ ). The $C_{\max }$ remained similar whether capsaicin was formulated in the LMP or not (CAPS 1 vs LMP CAPS $1, P=0.555$ ). Although the high capsaicin dose gave a higher $C_{\max }$ when the LMP formulation was used, the difference in $C_{\max }$ was not statistically significant (CAPS 2 vs LMP CAPS $2, P=0.068$ ).

\section{Discussion}

Our data demonstrate that the LMP formulation greatly improved the absorption of capsaicin in vivo. Increasing the bioavailability of poorly water-soluble compound might be an important alternative to other bioavailability enhancer technologies. This may be because LMP can improve the distribution of the compound in the gut, allowing for additional functionalities achieved through the appropriate selection of lipid excipients. Lipid-based delivery systems can enhance the bioavailability and functionality of drugs $[8,18]$ and bioactive compounds [23]. Recently, capsaicin-loaded lipid particle systems were developed to improve the transdermal delivery of capsaicin and reduce skin irritation [24, 25]. Zhu et al. [14] reported that

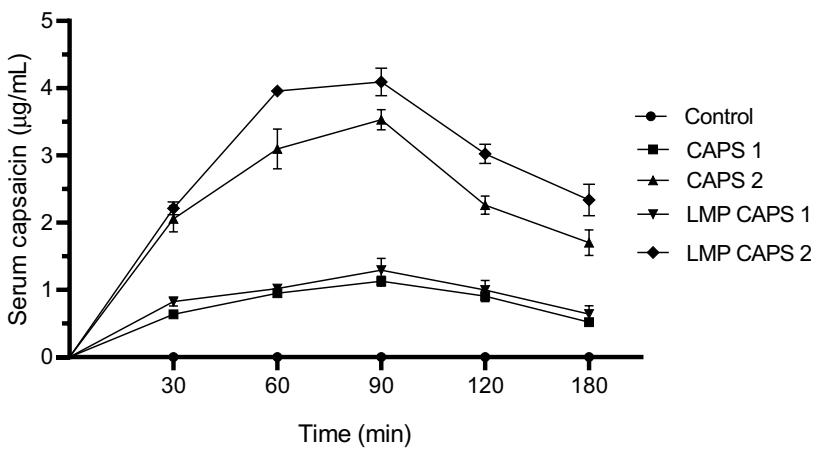

Fig. 2 Mean (SD) serum concentration-time profile of capsaicin following oral administration at $0.2 \mathrm{mg} / \mathrm{kg}$ (CAPS 1 ) or $1 \mathrm{mg} / \mathrm{kg}$ (CAPS 2 ) of capsaicin with or without the LMP formulation $(n=7)$ 
Table 1 Area under the concentration-time curve (AUC), time to peak serum concentration $\left(T_{\max }\right)$, and peak serum concentration $\left(C_{\max }\right)$ for oral capsaicin (CAPS) with or without the lipid multi-particulate (LMP) formulation

\begin{tabular}{llllll}
\hline Parameter & Group & & & \\
\cline { 2 - 5 } & Control & CAPS 1 & CAPS 2 & LMP CAPS 1 & LMP CAPS 2 \\
\hline AUC $(\mu \mathrm{g} \cdot \mathrm{h} /$ & $0.0(0.0-0.0)^{\mathrm{d}}$ & $128.4(117.4-139.3)^{\mathrm{c}}$ & $382.6(346.6-418.5)^{\mathrm{b}}$ & $145.8(121.1-170.6)^{\mathrm{c}}$ & $480.9(448.2-513.6)^{\mathrm{a}}$ \\
$\mathrm{mL})$ & & & & & \\
$T_{\max }(\min )$ & $0.0(0.0-0.0)^{\mathrm{b}}$ & $90.0(90.0-90.0)^{\mathrm{a}}$ & $90.0(37.0-123.0)^{\mathrm{a}}$ & $90.0(57.0-143.0)^{\mathrm{a}}$ & $60.0(27.0-113.0)^{\mathrm{a}}$ \\
$C_{\max }(\mu \mathrm{g} / \mathrm{mL})$ & $0.0(0.0-0.0)^{\mathrm{c}}$ & $1.20(0.82-1.44)^{\mathrm{b}}$ & $3.64(3.10-4.15)^{\mathrm{a}}$ & $1.38(0.97-1.79)^{\mathrm{b}}$ & $4.03(3.31-4.94)^{\mathrm{a}}$ \\
\hline
\end{tabular}

Data are presented as median (95\% confidence interval). Rats received $0.2 \mathrm{mg} / \mathrm{kg}$ (CAPS 1) or 1 (CAPS 2) of capsaicin with or without the LMP formulation $(n=7)$. Values in the same row with different superscript symbols $(\mathrm{a}-\mathrm{d})$ are statistically significantly different (ANOVA and Tukey's post-hoc test; $P<0.05)$.

liposomal encapsulation allowed a 3.34-fold increase in relative bioavailability compared to free capsaicin in rats. Furthermore, liposome-encapsulated capsaicin formulations may increase its solubility and oral bioavailability [13].

Based on the AUC, administering low-dose capsaicin as LMP formulation did not impact its bioavailability. At the high dose, however, the LMP-formulated capsaicin showed higher bioavailability than capsaicin without the LMP formulation. It is possible that high-dose capsaicin passes through the intestines without being absorbed because the amount absorbed during the intestinal transit is limited. Administration in an LMP formulation can delay capsaicin release, and this delayed release may lengthen the transit time, leading to more absorption of the high dose in the intestine. On the other hand, the low dose of capsaicin is probably absorbed within the transit time even when the LMP formulation is not used. $C_{\max }$ and $T_{\max }$ were not significantly impacted by the administration of capsaicin in the LMP formulation. Previous studies have reported that liposome-encapsulated capsaicin formulations [13] increased $T_{\max }$ and $C_{\max }$, whereas only $T_{\max }$ increased when capsaicinloaded micelles were administered to rats [14]. The AUC reflects the total serum exposure of capsaicin and is a measure of its bioavailability. $T_{\max }$ and $C_{\max }$, however, represent the rate of absorption. Therefore, it can be concluded that administration via the LMP formulation does not affect the rate of absorption but does increase the bioavailability of capsaicin at $1 \mathrm{mg} / \mathrm{kg}$.

LMPs are an innovation that enhance the performance of pharmaceutical products, and have been used in consumer health and nutrition applications. The ability of LMP to precisely deliver a metered dose of an active ingredient is probably the result of delayed release and increased transit time, leading to a better absorption of capsaicin. Therefore, in our case, the LMP formulation helped capsaicin to manifest itself in a more beneficial way and potentially by improving its therapeutic effects and enhancing its bioavailability, as demonstrated in our study. The findings of the present work may lead to novel opportunities and horizons of drug and supplement effectiveness in the treatment and prevention of various health issues.

\section{Conclusions}

In conclusion, this study investigated the serum concentrations of capsaicin with or without an LMP at different time intervals after oral administration. The present work demonstrated that LMP formulation significantly increased the bioavailability of oral capsaicin by $20 \%$ when administered at a dose of $1 \mathrm{mg} / \mathrm{kg}$. These results also demonstrate that capsaicin, an effective phytochemical with anti-inflammatory, antiobesity, antioxidation, and lipid-peroxidation-lowering effects, can be formulated with an LMP to enhance its oral bioavailability and potentially its efficacy.

\section{Declarations}

Funding This project was supported by Lonza Consumer Health Inc. (Morristown, NJ, USA) and by the Turkish Academy of Sciences (KS, Ankara, Turkey). The funding organizations were not involved in the study design, collection, analysis, and interpretation of data, the writing of this article or the decision to submit it for publication.

Conflict of Interest AB, SD, KF, and TW are employees of Lonza, who developed the LMP encapsulations. The other authors have no other relevant affiliations or financial involvement with any organization or entity with a financial interest in or financial conflict with the subject matter or materials discussed in the manuscript.

Ethical Approval All animal work was approved by the Animal Ethics Committee of Firat University (27/05/2020-393056) and was done following the standard ethical guidelines for laboratory animal use and care.

Consent to Participate Not applicable.

Consent for Publication Not applicable.

Availability of Data and Material The data presented in this study are available within the article.

Code Availability Not applicable.

Author Contributions $\mathrm{KS}$ and $\mathrm{AB}$ were involved in the conception and design; CO, MT, and ES performed the experiments and analyzed the 
samples; KF and TW prepared the capsaicin LMP formulation; OK drafted the manuscript; $\mathrm{OK}, \mathrm{KS}, \mathrm{AB}$, and $\mathrm{SD}$ revised the paper. All the authors read and approved the final version of the manuscript. All authors agree to be accountable for all aspects of the work. All authors reviewed the results and approved the final version of the manuscript.

Open Access This article is licensed under a Creative Commons Attribution-NonCommercial 4.0 International License, which permits any non-commercial use, sharing, adaptation, distribution and reproduction in any medium or format, as long as you give appropriate credit to the original author(s) and the source, provide a link to the Creative Commons licence, and indicate if changes were made. The images or other third party material in this article are included in the article's Creative Commons licence, unless indicated otherwise in a credit line to the material. If material is not included in the article's Creative Commons licence and your intended use is not permitted by statutory regulation or exceeds the permitted use, you will need to obtain permission directly from the copyright holder. To view a copy of this licence, visit http://creativecommons.org/licenses/by-nc/4.0/.

\section{References}

1. Anand P, Bley K. Topical capsaicin for pain management: therapeutic potential and mechanisms of action of the new high-concentration capsaicin 8\% patch. Br J Anaesth. 2011;107(4):490502. https://doi.org/10.1093/bja/aer260.

2. Joo JI, Kim DH, Choi JW, Yun JW. Proteomic analysis for antiobesity potential of capsaicin on white adipose tissue in rats fed with a high fat diet. J Proteome Res. 2010;9(6):2977-87. https://doi.org/10.1021/pr901175w.

3. Chen M, Xiao C, Jiang W, Yang W, Qin Q, Tan Q, Lian B, Liang Z, Wei C. Capsaicin Inhibits Proliferation and Induces Apoptosis in Breast Cancer by Down-Regulating FBI-1-Mediated NF- $\mathrm{\kappa B}$ Pathway. Drug Des Devel Ther. 2021;15:125-40. https://doi.org/ 10.2147/DDDT.S269901.

4. Sun F, Xiong S, Zhu Z. Dietary capsaicin protects cardiometabolic organs from dysfunction. Nutrients. 2016;8(5):174. https://doi. org/10.3390/nu8050174.

5. Xu W, Liu J, Ma D, Yuan G, Lu Y, Yang Y. Capsaicin reduces Alzheimer-associated tau changes in the hippocampus of type 2 diabetes rats. PLoS ONE. 2017;12(2): e0172477. https://doi.org/ 10.1371/journal.pone.0172477.

6. Zhang XY, Guo Z, Li TP, Sun T. Dietary capsaicin normalizes CGRP peptidergic DRG neurons in experimental diabetic peripheral neuropathy. Sci Rep. 2021;11(1):1704. https://doi.org/10. 1038/s41598-021-81427-w.

7. O'Neill J, Brock C, Olesen AE, Andresen T, Nilsson M, Dickenson AH. Unravelling the mystery of capsaicin: a tool to understand and treat pain. Pharmacol Rev. 2012;64(4):939-71. https://doi.org/ 10.1124/pr.112.006163.

8. Khan ZA, Tripathi R, Mishra B. Methotrexate: a detailed review on drug delivery and clinical aspects. Expert Opin Drug Deliv. 2012;9(2):151-69. https://doi.org/10.1517/17425247.2012. 642362.

9. Hayman M, Kam PCA. Capsaicin: a review of its pharmacology and clinical applications. Curr Anaesth Crit Care. 2008;19(5):338-43. https://doi.org/10.1016/j.cacc.2008.07.003. 19338-343.

10. Kawada T, Watanabe T, Katsura K, Takami H, Iwai K. Formation and metabolism of pungent principle of Capsicum fruits. XV. Microdetermination of capsaicin by high-performance liquid chromatography with electrochemical detection. J Chromatogr. 1985;329(1):99_ 105. https://doi.org/10.1016/s0021-9673(01)81899-9.
11. Koprdova S, Schürmann C, Peetz D, Dürbye T, Kolligs F, Koop H. Case report of presumed (in)voluntary capsaicin intoxication mimicking an acute abdomen. Case Rep Med. 2020;2020:3610401. https://doi.org/10.1155/2020/3610401.

12. Rollyson WD, Stover CA, Brown KC, Perry HE, Stevenson CD, McNees CA, et al. Bioavailability of capsaicin and its implications for drug delivery. J Control Release. 2014;196:96-105. https://doi. org/10.1016/j.jconrel.2014.09.027.

13. Zhu Y, Wang M, Zhang J, Peng W, Firempong CK, Deng W, et al Improved oral bioavailability of capsaicin via liposomal nanoformulation: preparation, in vitro drug release and pharmacokinetics in rats. Arch Pharm Res. 2015;38(4):512-21. https://doi.org/10. 1007/s12272-014-0481-7.

14. Zhu Y, Peng W, Zhang J, Wang M, Firempong CK, Feng C, et al. Enhanced oral bioavailability of capsaicin in mixed polymeric micelles: preparation, in vitro and in vivo evaluation. J Funct Foods. 2014;8:358-66. https://doi.org/10.1016/j.jff.2014.04.001.

15. Tavano L, Alfano P, Muzzalupo R, de Cindio B. Niosomes vs microemulsions: new carriers for topical delivery of Capsaicin. Colloids Surf B Biointerfaces. 2011;87(2):333-9. https://doi.org/ 10.1016/j.colsurfb.2011.05.041

16. Desai PR, Marepally S, Patel AR, Voshavar C, Chaudhuri A, Singh M. Topical delivery of anti-TNF $\alpha$ siRNA and capsaicin via novel lipid-polymer hybrid nanoparticles efficiently inhibits skin inflammation in vivo. J Control Release. 2013;170(1):51-63. https://doi.org/10.1016/j.jconrel.2013.04.021.

17. Granero GE, Longhi MR, Becker C, Junginger HE, Kopp S, Midha $\mathrm{KK}$, et al. Biowaiver monographs for immediate release solid oral dosage forms: acetazolamide. J Pharm Sci. 2008;97(9):3691-9. https://doi.org/10.1002/jps.21282.

18. Shukla D, Chakraborty S, Singh S, Mishra B. Lipid-based oral multiparticulate formulations - advantages, technological advances and industrial applications. Expert Opin Drug Deliv. 2011;8(2):207-24. https://doi.org/10.1517/17425247.2011.547469.

19. Lo JB, Appel LE, Herbig SM, McCray SB, Thombre AG. Formulation design and pharmaceutical development of a novel controlled release form of azithromycin for single-dose therapy. Drug Dev Ind Pharm. 2009;35(12):1522-9. https://doi.org/10.3109/ 03639040903037223

20. Urbina SL, Roberts MD, Kephart WC, Villa KB, Santos EN, Olivencia AM, Bennett HM, Lara MD, Foster CA, Purpura M, Jäger R, Taylor LW, Wilborn CD. Effects of twelve weeks of capsaicinoid supplementation on body composition, appetite and self-reported caloric intake in overweight individuals. Appetite. 2017;113:264-73. https://doi.org/10.1016/j.appet.2017.02.025.

21. Suresh D, Srinivasan K. Tissue distribution \& elimination of capsaicin, piperine and curcumin following oral intake in rats. Indian J Med Res. 2010;131:682-91.

22. ICH. Technical requirements for the registration of pharmaceuticals for human use; validation of analytical procedures: text and methodology (Q2(R1)). Geneva: IFPMA; 2005.

23. Gasa-Falcon A, Odriozola-Serrano I, Oms-Oliu G, Martín-Belloso O. Nanostructured Lipid-Based Delivery Systems as a Strategy to Increase Functionality of Bioactive Compounds. Foods. 2020;9(3):325. https://doi.org/10.3390/foods9030325.

24. Anantaworasakul P, Chaiyana W, Michniak-Kohn BB, Rungseevijitprapa W, Ampasavate C. Enhanced Transdermal Delivery of Concentrated Capsaicin from Chili Extract-Loaded Lipid Nanoparticles with Reduced Skin Irritation. Pharmaceutics. 2020;12(5):463. https://doi.org/10.3390/pharmaceutics12050463.

25. Raza K, Shareef MA, Singal P, Sharma G, Negi P, Katare OP. Lipid-based capsaicin-loaded nano-colloidal biocompatible topical carriers with enhanced analgesic potential and decreased dermal irritation. J Liposome Res. 2014;24(4):290-6. https://doi.org/ 10.3109/08982104.2014.911314. 